Article

\title{
Modified graphene-based materials as effective catalysts for transesterification of rapeseed oil to biodiesel fuel
}

\author{
Justina Gaidukevič a,*, Jurgis Barkauskas a, Anna Malaika b,\#, Paulina Rechnia-Gorący b, \\ Aleksandra Możdżyńska b, Vitalija Jasulaitienè c, Mieczysław Kozłowski b \\ a Faculty of Chemistry and Geosciences, Institute of Chemistry, Vilnius University, Naugarduko 24, LT-03225 Vilnius, Lithuania \\ b Faculty of Chemistry, Adam Mickiewicz University in Poznań, Umultowska 89b, 61-614 Poznań, Poland \\ c State Research Institute Centre for Physical Sciences and Technology, Sauletekio 3, LT-10257 Vilnius, Lithuania
}

\section{A R T I C L E I N F}

\section{Article history:}

Received 23 March 2018

Accepted 17 April 2018

Published 5 October 2018

\section{Keywords:}

Graphene

Surface functionalization

Acidic catalyst

Sulfonic group

Transesterification

Biodiesel

\begin{abstract}
A B S T R A C T
Production of biodiesel by the transesterification process using different modified graphene-based materials as catalysts was studied. Solid acid graphene-based samples were prepared by grafting sulfonic or phosphate groups on the surface of thermally reduced graphene oxide. The obtained materials were thoroughly characterized using scanning electron microscopy, X-ray diffraction, thermogravimetric analysis, X-ray photoelectron spectroscopy, $\mathrm{N}_{2}$ adsorption-desorption measurements, potentiometric titration, elemental analysis, and Fourier transform infrared spectroscopy. The prepared catalysts were tested in the transesterification of rapeseed oil with methanol at $130{ }^{\circ} \mathrm{C}$ under pressure, and their activities were compared to the performance of a commercially available heterogeneous acidic catalyst, Amberlyst-15. All modified samples were active in the transesterification process; however, significant differences were observed in the yield of biodiesel, depending on the method of catalyst preparation and strength of the acidic sites. The highest yield of fatty acid methyl esters of 70\% was obtained for thermally reduced graphene oxide functionalized with 4-benzenediazonium sulfonate after $6 \mathrm{~h}$ of processing, and this result was much higher than that obtained for the commercial catalyst Amberlyst-15. The results of the reusability test were also promising.
\end{abstract}

(C) 2018, Dalian Institute of Chemical Physics, Chinese Academy of Sciences. Published by Elsevier B.V. All rights reserved.

\section{Introduction}

Fossil fuels (petroleum, coal, and natural gas) are the main sources of energy in many parts of the world. However, the strong dependence on these non-renewable resources has raised serious concerns. First, experts have warned about the rapid depletion of fossil fuels, which is mainly related to the increasing world population, industrial and technological developments, and increasing demand for energy in developed and developing countries. Second, combustion of fossil fuels generates many harmful products, e.g., carbon dioxide, nitrogen oxides, or particulate matter. Because of the aforementioned reasons, current research is focused on seeking fuels that are renewable and sustainable. The above approach also includes a gradual replacement of conventional diesel fuel by more environmentally friendly and biodegradable biodiesel [1,2].

Biodiesel is a mixture of fatty acid methyl esters (FAMEs) and is usually produced through the transesterification of vegetable oils or animal fats with an alcohol in the presence of a catalyst [1]. Traditionally, strong Brønsted bases, such as so-

\footnotetext{
* Corresponding author. Tel: +370-5-2234610; E-mail: justina.gaidukevic@chf.vu.lt

\# Corresponding author. E-mail: amalaika@amu.edu.pl

DOI: 10.1016/S1872-2067(18)63087-6 | http://www.sciencedirect.com/science/journal/18722067 | Chin. J. Catal., Vol. 39, No. 10, October 2018
} 
dium or potassium hydroxide, or strong Brønsted acids, such as $\mathrm{H}_{2} \mathrm{SO}_{4}$ or $\mathrm{H}_{3} \mathrm{PO}_{4}$, are used as homogenous catalysts for the transesterification reaction. However, the expensive separation of such catalysts from the reaction mixture has encouraged the development of heterogeneous systems for this process [3]. Solid catalytic systems have several advantages over homogeneous ones: they can be easily separated for reuse, they show less corrosive and toxic effects, and they are much more tolerant to water and free fatty acids (FFAs) in the feedstock [4]. For the last few years, there have been extensive studies on the performance of heterogeneous catalysts in transesterification reactions. Among the most commonly used systems are metal oxides or sulfides, zeolites, heteropoly acids, hydrotalcites, ion-exchange resins, basic oxides, and organic bases $[4,5]$. However, although the aforementioned materials are promising catalysts for biodiesel production, they still suffer from numerous drawbacks, e.g., easy deactivation, high cost, low thermal stability, and/or harmful effects on the environment because of the presence of certain metals [5]. In view of the above, current research is often focused on nanostructured carbon materials, which can be easily obtained using simple and economically viable methods, have tunable textural and chemical properties, and show a great catalytic potential [6-10].

Different carbon materials, including fullerenes, activated carbons, carbon nanotubes, and graphene, have been used in various processes as effective catalysts or catalyst supports [10-14]. Among them, graphene and its derivatives have attracted particular attention recently. Their usefulness in catalysis results from the following features: high theoretical specific surface area (up to $2630 \mathrm{~m}^{2} / \mathrm{g}$ ) and high chemical, thermal, optical, and electrochemical stabilities, which can potentially improve the lifetime of a catalyst. Moreover, the superior electron mobility of graphene facilitates electron transfer during the catalytic reactions, improving the catalytic activity $[7,15,16]$. Finally, chemically modified graphene, such as graphene oxide and reduced graphene oxide (also called "functionalized graphene sheets" [17]), can be obtained on a large scale at a relatively low cost using graphite as the starting material [18].

Literature concerning the use of graphene-based catalysts in the process of oil transesterification is very scarce. One of the most interesting papers regarding this topic was written by Nongbe et al. [19]. The authors reported that sulfonated graphene showed an excellent catalytic performance towards the transesterification of palm oil with methanol (yield of FAME, 98\%). However, high methanol-to-oil molar ratio (20:1) and high catalyst loading (10 wt\%) were used in this study. Although the methods of acid carbon catalyst preparation are relatively simple, it is still challenging to obtain materials with a high density of catalytic centers and to prevent these active sites against leaching from the carbon structure [10].

Taking the above into account, in the present study, we showed that thermally reduced graphene oxide (TRGO) modified with 4-benzenediazonium sulfonate (BDS), $\mathrm{H}_{2} \mathrm{SO}_{4}$, or $\mathrm{H}_{3} \mathrm{PO}_{4}$ can be a promising solid acid catalyst to produce biodiesel from rapeseed oil, even when a relatively low molar ratio of methanol to oil and catalyst loading are used. The catalytic activity and reusability of the samples were investigated and compared to the catalytic performance of a commercial catalyst, Amberlyst-15. The characterization of the graphene-based materials was performed, and the correlation between the structure of the catalysts and their performance in the transesterification reaction was discussed.

\section{Experimental}

\subsection{Materials and reagents}

The graphite used for the synthesis was of extra-pure grade. According to the manufacturer's data (Merck), its particle size was $\geq 50 \mu \mathrm{m}(\geq 99.5 \%)$. Commercially available rapeseed oil purchased in Poland was used in this work. All other reagents were of analytical grade or high purity and were used as received without further purification.

\subsection{Preparation of catalysts}

\subsubsection{Synthesis of graphite oxide (GO) and TRGO}

GO was synthesized from graphite according to the protocol reported by Yan et al. [20]. In a typical experiment, graphite powder was treated with concentrated $\mathrm{H}_{2} \mathrm{SO}_{4}, \mathrm{~K}_{2} \mathrm{~S}_{2} \mathrm{O}_{8}$, and $\mathrm{P}_{2} \mathrm{O}_{5}$. The pre-oxidized sample obtained in this way was then subjected to oxidation by Hummers' method using $\mathrm{NaNO}_{3}, \mathrm{H}_{2} \mathrm{SO}_{4}$, and $\mathrm{KMnO}_{4}$ [21]. Afterwards, the prepared GO was washed thoroughly with distilled water until the $\mathrm{pH}$ of the filtrate was neutral. Finally, the obtained brown powder was dried in a desiccator to a constant weight. The simultaneous thermal exfoliation and reduction of GO was performed following the procedure described elsewhere [22]. Typically, the dried GO powder $(\sim 0.05 \mathrm{~g})$ was quickly inserted into a vertical reactor that had been preheated by a tubular furnace (temperature of about $800{ }^{\circ} \mathrm{C}$ ). During this treatment, the argon flow rate through the reactor was maintained at $100 \mathrm{~mL} / \mathrm{min}$. The TRGO sample was then modified with different agents in order to introduce acidic functional groups on its surface.

\subsubsection{Functionalization of TRGO with concentrated $\mathrm{H}_{2} \mathrm{SO}_{4}$}

The treatment of TRGO with concentrated $\mathrm{H}_{2} \mathrm{SO}_{4}$ was performed as follows: TRGO (3.0 g) and concentrated $\mathrm{H}_{2} \mathrm{SO}_{4}(95$ wt $\%, 140 \mathrm{~mL}$ ) were placed in a three-neck round-bottom flask and heated at $140{ }^{\circ} \mathrm{C}$ for 5 or $20 \mathrm{~h}$ under an argon flow with continuous stirring. Then, the suspension was cooled to room temperature, and the obtained material was filtered and thoroughly washed with hot distilled water $\left(60^{\circ} \mathrm{C}\right)$. Finally, the sample was dried overnight at $110{ }^{\circ} \mathrm{C}$ and sieved to a uniform size range $(\leq 0.4 \mathrm{~mm})$. The resultant catalysts are denoted as TRGO- $\mathrm{H}_{2} \mathrm{SO}_{4}-5$ and TRGO- $\mathrm{H}_{2} \mathrm{SO}_{4}-20$, where 5 and 20 represent the treatment time.

\subsubsection{Functionalization of TRGO with BDS}

Functionalization of TRGO with the diazonium cation generated in situ was performed according to a modified method proposed by Toupin et al. [23]. Briefly, TRGO (2.0 g) was dispersed in distilled water $(100 \mathrm{~mL})$; then, an equimolar amount 
of 4-aminobenzenesulfonic acid (2.87 g) and $\mathrm{NaNO}_{2}$ (1.15 g) was introduced into the mixture; finally, concentrated $\mathrm{HCl}(20$ $\mathrm{mL}$ ) was added dropwise. The reaction was carried out at ambient temperature for $20 \mathrm{~h}$ under continuous stirring. The prepared catalyst was filtered and washed with distilled water, methanol, dimethylformamide, and acetone. Subsequently, the obtained material was dried overnight at $110^{\circ} \mathrm{C}$ and sieved to a uniform size range $(\leq 0.4 \mathrm{~mm})$. The resultant sample is denoted as TRGO-BDS.

\subsubsection{Functionalization of TRGO with $\mathrm{H}_{3} \mathrm{PO}_{4}$}

The modification of TRGO using $\mathrm{H}_{3} \mathrm{PO}_{4}$ was performed as follows [24]: the initial TRGO (2.5 g) was impregnated with a $\mathrm{H}_{3} \mathrm{PO}_{4}$ solution $(7.0 \%, 53.8 \mathrm{~g})$ at ambient temperature for $4 \mathrm{~h}$ under mechanical stirring. After this time, the mixture was dried overnight at $190{ }^{\circ} \mathrm{C}$. Then, the impregnated sample was thermally treated at $800{ }^{\circ} \mathrm{C}$ for 30 min under a nitrogen flow. To remove any remaining $\mathrm{H}_{3} \mathrm{PO}_{4}$, the material was extensively washed with hot distilled water until a neutral $\mathrm{pH}$ value was attained for the filtrate. Finally, the catalyst was dried overnight at $110{ }^{\circ} \mathrm{C}$ and sieved to a uniform size range $(\leq 0.4 \mathrm{~mm})$. The resultant sample is denoted as TRGO- $\mathrm{H}_{3} \mathrm{PO}_{4}$.

\subsection{Catalyst characterization}

The textural properties of the obtained materials were determined on the basis of nitrogen adsorption at $-196^{\circ} \mathrm{C}$ using a Quantachrome Autosorb iQ analyzer. Prior to the gas sorption measurements, all the samples were outgassed in vacuum at $150{ }^{\circ} \mathrm{C}$. The total surface areas of the carbons $\left(S_{\text {BET }}\right)$ were calculated using the Brunauer-Emmett-Teller (BET) model, whereas the $t$-plot method was used to estimate the micropore volume $\left(V_{\mu}\right)$ and external surface area (of meso- and macropores; $S_{\text {ext }}$ ) [25]. The total pore volume $\left(V_{\text {tot }}\right)$ was obtained from the amount of $\mathrm{N}_{2}$ adsorbed at a relative pressure close to unity. Scanning electron microscopy (SEM) images were obtained using a Hitachi SU-70 microscope at an accelerating voltage of $5.0 \mathrm{kV}$ and magnification of 25000 . X-ray diffraction (XRD) studies were performed using a MiniFlex II (Rigaku) diffractometer with $\mathrm{Cu} K_{\alpha}\left(K_{\alpha 1}=1.54056 \AA\right)$ radiation for $2 \theta$ values from $5^{\circ}$ to $55^{\circ}$. The XRD characterization was done at $30 \mathrm{kV}$ and $15 \mathrm{~mA}$ with a step size of $0.01^{\circ}$ and a dwell time of $1.0 \mathrm{~s}$. Fourier transform infrared (FTIR) measurements were carried out using a PerkinElmer FTIR spectrometer in the range of $600-4000 \mathrm{~cm}^{-1}$. The spectra were recorded using the $\mathrm{KBr}$ pellet technique. Thermogravimetric (TG) analysis was performed using a PerkinElmer Pyris 1 instrument at a heating rate of $10{ }^{\circ} \mathrm{C} / \mathrm{min}$ from room temperature to $800{ }^{\circ} \mathrm{C}$ under $\mathrm{N}_{2}$ purge gas. Quantitative elemental analysis (EA) of $\mathrm{C}, \mathrm{H}, \mathrm{N}$ and $\mathrm{S}$ was performed using a vario EL III elemental analyzer (Elementar). The content of phosphorus was determined using a Varian ICP-OES Vista MPX apparatus. The ash content was determined as the residue after combustion. The total acidity and basicity of the graphene-based catalysts was determined by a potentiometric back-titration method using a Cerko Lab System titrator. X-ray photoelectron spectroscopy (XPS) analyses were performed using a VG Scientific ESCALAB MKII (Thermo Fisher
Scientific) spectrometer equipped with a non-monochromatized $\mathrm{Mg} K_{\alpha} \mathrm{X}$-ray source $(h v=1253.6 \mathrm{eV})$. The spectra were acquired with an electron analyzer pass energy of $20 \mathrm{eV}$ and calibrated using the $\mathrm{C} 1 s$ peak at $284.6 \mathrm{eV}$. Core-level peaks were analyzed using a nonlinear Shirley-type background subtraction, and the calculation of the elemental composition was performed on the basis of Scofield's relative sensitivity factors.

\subsection{Transesterification reaction procedure}

The transesterification reaction between rapeseed oil and methanol was investigated.

A typical experiment was carried out in a stainless steel autoclave loaded with $50 \mathrm{~mL}$ of rapeseed oil and $24.4 \mathrm{~mL}$ of methanol. Then, $0.446 \mathrm{~g}$ of a graphene-based catalyst was added to the reactor. The system was thoroughly flushed with argon to remove air. The transesterification process was conducted at $130{ }^{\circ} \mathrm{C}$ for $24 \mathrm{~h}$ under an argon atmosphere at a pressure of 1.3 MPa. During the reaction, four samples of the reaction mixture were collected (after 1, 3, 6, and $24 \mathrm{~h}$ ) and centrifuged at $10000 \mathrm{r} / \mathrm{min}$ for $5 \mathrm{~min}$. The separated ester phase was washed with distilled water three times to remove the residual glycerol, methanol, and catalyst. The obtained ester product was finally dried with anhydrous $\mathrm{MgSO}_{4}$ and analyzed using an SRI 8610C gas chromatograph (GC) equipped with a flame ionization detector (FID) and an InertCap WAX capillary column $(30 \mathrm{~m} \times 0.51 \mathrm{~mm} \times 1 \mu \mathrm{m})$. Helium was used as a carrier gas, $\mathrm{n}$-heptane was used as a solvent, and methyl heptadecanoate was used as an internal standard. The temperature of the GC oven was first kept at $180^{\circ} \mathrm{C}$ for $4 \mathrm{~min}$, then increased to $210{ }^{\circ} \mathrm{C}$ at a heating rate of $10^{\circ} \mathrm{C} / \mathrm{min}$ and held at this temperature for $33 \mathrm{~min}$. The general scheme of the transesterification reaction and an exemplary chromatogram are presented in Fig. 1(a) and (b), respectively. The yield of methyl esters was determined using a formula given in the literature [26]. For the selected sample (TRGO-BDS), reusability tests were conducted. The purification of the catalyst after each transesterification cycle was performed as follows: after finishing the reaction, the catalyst was separated from the reaction solution by filtration and thoroughly washed with acetone and hot distilled water to remove impurities attached to the catalyst surface. The washed catalyst was subsequently treated with $5 \% \mathrm{HCl}(30 \mathrm{~mL})$ for 20 $\mathrm{h}$ with continuous stirring. Then, the sample was washed with hot distilled water, dried overnight at $110{ }^{\circ} \mathrm{C}$, and reused for the next cycle of transesterification of rapeseed oil with methanol.

\section{Results and discussion}

\subsection{Characterization of the samples}

\subsubsection{Elemental and textural analysis}

Table 1 presents data on the chemical composition of the obtained samples and their acid-base properties. The results clearly indicate that oxidation of graphite was very efficient, as this process resulted in a tremendous increase in the oxygen 
(a)<smiles>[R1]C(=O)OCC(COC([R1])=O)OC([Y2])=O</smiles>

(b)

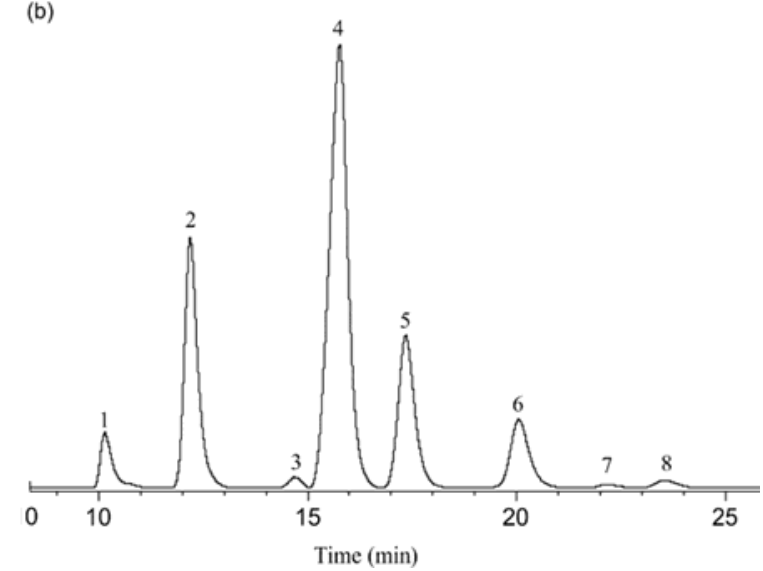

Fig. 1. General scheme of the transesterification reaction, where $R_{1}-R_{3}$ are the carbon chains of fatty acids (a), gas chromatogram (GC) of a biodiesel sample obtained after $24 \mathrm{~h}$ of the transesterification reaction between rapeseed oil and methanol with the following TRGO-BDS catalysts: 1-methyl palmitate, 2-methyl heptadecanoate (internal standard), 3-methyl stearate, 4-methyl oleate, 5-methyl linoleate, 6-methyl linolenate, 7-methyl arachidate, and 8-methyl eicosanoate (b).

content (from 0.2 to over $43 \mathrm{wt} \%$ ). The introduction of oxygen-containing groups was accompanied by an increase in the total acidity of GO (up to about $3.7 \mathrm{mmol} / \mathrm{g}$ ). During simultaneous thermal exfoliation and reduction of GO, some of the oxygen groups underwent decomposition; this is why the oxygen content substantially decreased.

However, it is worth emphasizing that even such a drastic treatment $\left(800{ }^{\circ} \mathrm{C}\right)$ led to the product which still contained a high amount of oxygen. This result indicates that the majority of oxygen functionalities present in TRGO are thermally stable (at least at $800{ }^{\circ} \mathrm{C}$ ), which in turn can suggest the presence of carbonyl, quinone, or pyrone structures in the reduced sample $[27,28]$. On the other hand, because the reduction time was rather short, it is also possible that part of the less thermally stable groups could also remain in the sample. This may explain why TRGO still shows some acidity.

The functionalization of TRGO with $\mathrm{H}_{2} \mathrm{SO}_{4}$ or BDS caused an increase in the oxygen content, which could be a consequence of introducing oxygen-containing sulfonic groups into the graphene structure. However, as suggested in the literature, hot concentrated $\mathrm{H}_{2} \mathrm{SO}_{4}$ is a strong oxidizing agent; upon contact with carbonaceous materials, it can also generate carboxylic groups [29]. This phenomenon was observed by Rechnia et al. [30] in the case of $\mathrm{H}_{2} \mathrm{SO}_{4}$-modified activated carbons. On the other hand, the reaction of TRGO with $\mathrm{H}_{3} \mathrm{PO}_{4}$ did not increase the oxygen content. In fact, a drop in the oxygen content was observed. This can support the hypothesis given above that TRGO also contains some thermally less-stable oxygen functionalities that decompose during the preparation of the TRGO- $\mathrm{H}_{3} \mathrm{PO}_{4}$ sample $\left(30 \mathrm{~min}\right.$ of heating at $\left.800{ }^{\circ} \mathrm{C}\right)$. However, a consequence of the TRGO modification with $\mathrm{H}_{3} \mathrm{PO}_{4}$ is the introduction of P-containing groups into the material framework. This is manifested by the increase in the P content and total acidity.

As can be seen from the EA results, GO and TRGO contain some nitrogen and sulfur. This situation may suggest that the nitrates, sulfates, or even $\mathrm{H}_{2} \mathrm{SO}_{4}$ were not completely washed out of the bulk GO phase after the oxidation step $\left(\mathrm{H}_{2} \mathrm{SO}_{4}\right.$, $\mathrm{K}_{2} \mathrm{~S}_{2} \mathrm{O}_{8}$, and $\mathrm{NaNO}_{3}$ were used in this process). In the case of the TRGO-BDS sample, a significant increase in the content of sulfur was observed. This indicates that the applied modification (aimed at introducing sulfonic groups) was successful. This conclusion is also confirmed by the substantial increase in the acidity of the sample. Additionally, an increase in the $\mathrm{N}$ content was seen for this material. According to the literature, this may indicate the presence of diazo linkages between the $-\mathrm{Ph}_{-} \mathrm{SO}_{3} \mathrm{H}$ groups and graphene sheets [31]. The sulfur content decreased slightly after the TRGO modification with $\mathrm{H}_{2} \mathrm{SO}_{4}$ or $\mathrm{H}_{3} \mathrm{PO}_{4}$, which could suggest that the residual sulfur compounds mentioned earlier were partly removed in a strong acidic medium. Furthermore, this result also indicates that for the

Table 1

Element contents of catalyst samples determined by EA and XPS, and the total acidity/basicity results.

\begin{tabular}{|c|c|c|c|c|c|c|c|c|c|}
\hline \multirow{2}{*}{ Analysis } & \multirow{2}{*}{ Sample } & \multicolumn{6}{|c|}{ wt\% (dry basis) } & \multirow{2}{*}{$\begin{array}{c}\text { Total acidity } \\
(\mathrm{mmol} / \mathrm{g})\end{array}$} & \multirow{2}{*}{$\begin{array}{c}\text { Total basicity } \\
\text { (mmol/g) }\end{array}$} \\
\hline & & Ash & $\mathrm{C}$ & $\mathrm{H}$ & $\mathrm{N}$ & $\mathrm{S}(\mathrm{P})$ & $\mathrm{O}^{\mathrm{a}}$ & & \\
\hline \multirow[t]{8}{*}{ EA } & Graphite & 0.0 & 99.7 & 0.1 & 0.0 & 0.0 & 0.2 & 0.04 & 0.06 \\
\hline & GO & 1.5 & 51.0 & 2.3 & 0.1 & 1.8 & 43.3 & 3.74 & 0.00 \\
\hline & TRGO & 1.5 & 83.3 & 1.2 & 0.3 & 2.0 & 11.7 & 0.83 & 0.00 \\
\hline & TRGO- $\mathrm{H}_{2} \mathrm{SO}_{4}-5$ & 0.5 & 82.9 & 1.1 & 0.4 & 1.5 & 13.6 & 1.03 & 0.00 \\
\hline & TRGO- $\mathrm{H}_{2} \mathrm{SO}_{4}-20$ & 1.2 & 81.9 & 1.1 & 0.3 & 1.6 & 13.9 & 1.09 & 0.00 \\
\hline & TRGO-BDS & 1.3 & 73.8 & 2.1 & 0.8 & 4.7 & 17.3 & 1.46 & 0.00 \\
\hline & TRGO- $\mathrm{H}_{3} \mathrm{PO}_{4}$ & 9.4 & 75.4 & 1.4 & 0.3 & $1.3(7.2)$ & 5.0 & 1.38 & 0.00 \\
\hline & Amberlyst-15 & - & - & - & - & - & - & $4.70^{b}$ & - \\
\hline \multirow[t]{4}{*}{ XPS } & TRGO & - & 82.6 & - & 0.0 & 2.6 & 14.8 & - & - \\
\hline & TRGO- $\mathrm{H}_{2} \mathrm{SO}_{4}-20$ & - & 83.0 & - & 0.0 & 2.9 & 14.1 & - & - \\
\hline & TRGO-BDS & - & 73.1 & - & 0.9 & 8.1 & 17.9 & - & - \\
\hline & TRGO- $\mathrm{H}_{3} \mathrm{PO}_{4}$ & - & 79.6 & - & 0.0 & $0.0(7.6)$ & 12.8 & - & - \\
\hline
\end{tabular}

a Calculated by difference.

b Manufacturer's data. 
$\mathrm{H}_{2} \mathrm{SO}_{4}$-treated samples, the above process dominates over the possible and desired formation of sulfonic groups. However, the results of the EA do not determine whether sulfonic groups are really formed. On the other hand, a slight increase in the total acidity is finally observed, but this can be a consequence of the generation of carboxylic groups, as mentioned earlier. Nevertheless, the data clearly indicate that TRGO modification with $\mathrm{H}_{2} \mathrm{SO}_{4}$ is much less effective than TRGO treatment with diazonium salt generated in situ.

All modified samples contain some ash. The origin of ash in the carbons may be related to the presence of incombustible substances (chlorine, potassium, phosphorus compounds, etc.) that could be introduced during the chemical treatment of graphite or intermediate products and, as already suggested, were not completely washed from the structure of the samples. An exceptionally high ash content is present in TRGO- $\mathrm{H}_{3} \mathrm{PO}_{4}$ (9.4\%), which also has a high phosphorus content (7.2\%). This indicates that phosphorus mainly accumulates in the ash fraction after combustion.

The results obtained by XPS exhibit some differences with respect to the results obtained by means of EA (Table 1); however, the conclusions drawn on their basis are similar. As follows from the analysis of the data, the contents of oxygen, sulfur, and phosphorus obtained by XPS are greater than those from EA. On the other hand, the XPS data show the absence of sulfur in TRGO- $\mathrm{H}_{3} \mathrm{PO}_{4}$ and nitrogen in all the catalyst samples (except TRGO-BDS). This can be justified since XPS is a more sensitive surface technique (penetrating $10 \mathrm{~nm}$ from the surface) than EA, which provides bulk analysis. No essential differences are noted between the surface and the bulk content of carbon. Similarly, as in the case of EA, the highest contents of sulfur and nitrogen are observed for the TRGO-BDS sample, and this confirms that $-\mathrm{Ph}-\mathrm{SO}_{3} \mathrm{H}$ functionalities were attached to graphene layers, mainly via $-\mathrm{N}=\mathrm{N}$ - bonds.

Table 2 depicts the results regarding the textural parameters of the samples. The specific surface areas of graphite and GO are rather small, and the samples show a practically nonporous character. The porous structure formed during thermal reduction of GO when the oxygen functional groups were decomposed as a result of heating and were removed from the sample in the gas phase (see results of the EA). TRGO does not contain micropores, and the significant increase in the textural parameters, such as $S_{\mathrm{BET}}, S_{\text {ext }}$ and $V_{\text {tot, }}$ is a consequence of exfoliation and separation of graphene layers during the

Table 2

Textural characterization of the samples.

\begin{tabular}{lrrcc}
\hline Sample & $\begin{array}{c}S_{\text {BET }} \\
\left(\mathrm{m}^{2} / \mathrm{g}\right)\end{array}$ & $\begin{array}{c}S_{\text {ext }} \\
\left(\mathrm{m}^{2} / \mathrm{g}\right)\end{array}$ & $\begin{array}{c}V_{\text {tot }} \\
\left(\mathrm{cm}^{3} / \mathrm{g}\right)\end{array}$ & $\begin{array}{c}V_{\mu} \\
\left(\mathrm{cm}^{3} / \mathrm{g}\right)\end{array}$ \\
\hline Graphite & 12 & 11 & 0.03 & 0.00 \\
GO & 46 & 41 & 0.17 & 0.00 \\
TRGO & 617 & 617 & 3.82 & 0.00 \\
TRGO- $_{2} \mathrm{SO}_{4}-5$ & 485 & 468 & 2.20 & 0.01 \\
TRGO-H$_{2} \mathrm{SO}_{4}-20$ & 513 & 511 & 2.29 & 0.00 \\
TRGO-BDS & 422 & 413 & 2.76 & 0.00 \\
TRGO-H$_{3} \mathrm{PO}_{4}$ & 300 & 206 & 0.99 & 0.05 \\
Amberlyst-15 & 53 & - & 0.40 & - \\
TRGO-BDS after the $4{ }^{\text {th }}$ run & 348 & 341 & 1.51 & 0.00 \\
\hline
\end{tabular}

a Manufacturer's data. above-mentioned gas removal. Subsequent modifications of TRGO led to a reduction in the textural parameters of these materials, which is probably related to the introduction of various functionalities that occupy some space between layers.

\subsubsection{SEM analysis}

In order to investigate changes in the morphology of the samples, SEM analysis of the precursor, intermediate products, and final catalysts was performed. The SEM micrographs are presented in Fig. 2(a)-(g). For the sake of comparison, a SEM image of Amberlyst-15 is also depicted (Fig. 2(h)). Fig. 2(a) shows the fissured nature of the graphite particles; this is distinctly different from the structures presented by other samples. The oxidative treatment of graphite substantially changed its morphological features (Fig. 2(b)). The GO surface became more wrinkled, which may be related to the increase in interlayer spacing in graphite by oxygen groups. The thermal treatment of GO combined with decomposition of these oxygen functionalities provided a porous "fluffy" structure, in which the exfoliated fragments are clearly visible (Fig. 2(c)). Modifications of TRGO with particular reagents were reflected by detectable changes in the sample morphology. The treatment with $\mathrm{H}_{2} \mathrm{SO}_{4}$ had a significant effect on the edge structure of the
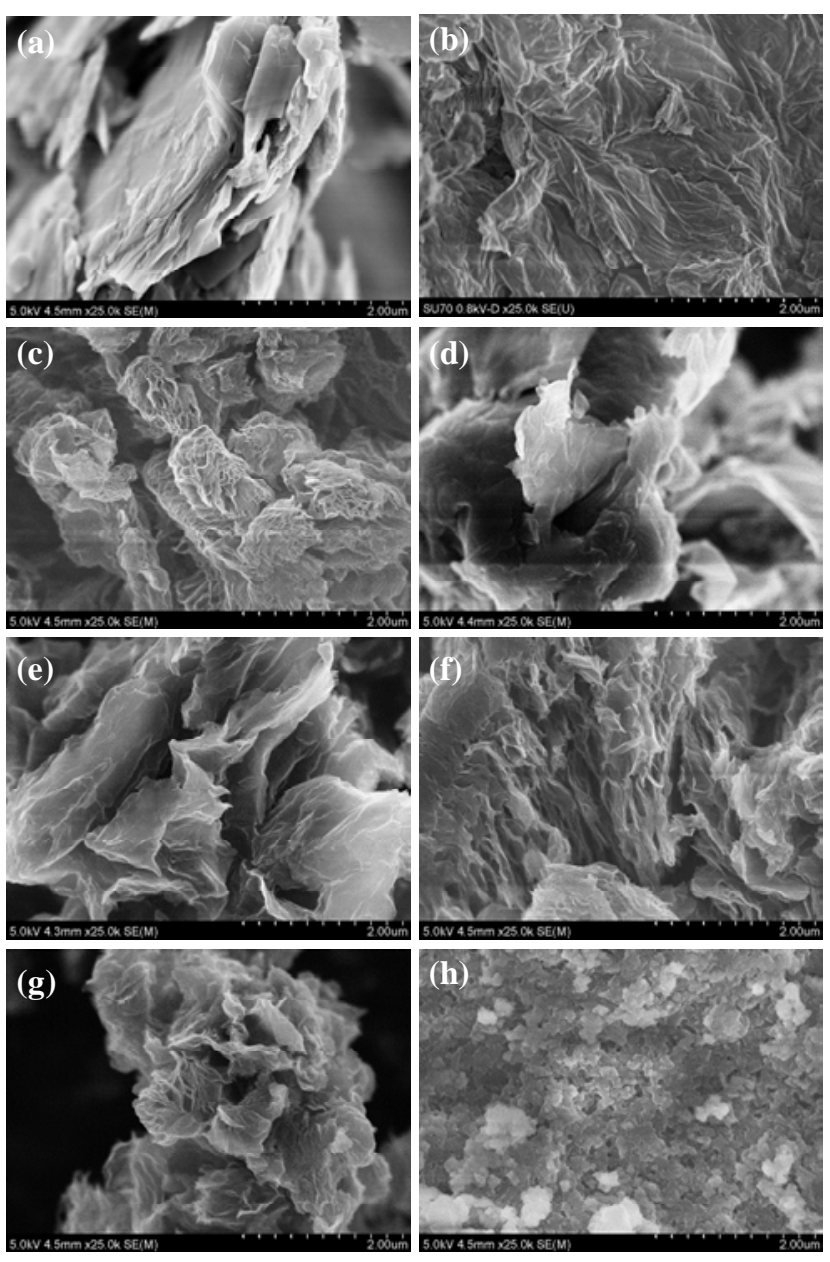

Fig. 2. SEM images of the precursor, intermediate products, and catalysts used in the study. (a) graphite, (b) GO, (c) TRGO, (d) TRGO- $\mathrm{H}_{2} \mathrm{SO}_{4}-5$, (e) TRGO- $\mathrm{H}_{2} \mathrm{SO}_{4}-20$, (f) TRGO-BDS, (g) TRGO- $\mathrm{H}_{3} \mathrm{PO}_{4}$, (h) Amberlyst-15. 
particles (Fig. 2(d) and (e)), as the flake-like forms are clearly visible after modification. On the other hand, the morphology of the sample functionalized with BDS (Fig. 2(f)) was quite similar to that of TRGO. Similarly, the catalyst sample modified with $\mathrm{H}_{3} \mathrm{PO}_{4}$ resembles pristine TRGO (Fig. 2(g)). This is probably a consequence of BDS and $\mathrm{H}_{3} \mathrm{PO}_{4}$ being relatively mild modifying agents, providing small changes, whereas $\mathrm{H}_{2} \mathrm{SO}_{4}$ is a much more aggressive substance and thus leads to larger alterations in the carbon structure. As can be seen in Fig. 2(h), the morphology of Amberlyst-15 is substantially different from that of the graphene-based materials.

\subsubsection{XRD analysis}

The differences in the structures of the samples are reflected in their XRD patterns (Fig. 3). In the XRD pattern of graphite, a sharp basal reflection peak (002) at $2 \theta=26.70^{\circ}$, corresponding to a $d$ spacing of 0.335 , is present. Some less-intensive peaks are detected at $2 \theta=42.36^{\circ}(001), 2 \theta=44.56^{\circ}(101)$, and $2 \theta=55.66^{\circ}(004)$. The peaks in the diffractogram of GO $(2 \theta=$ $10.35^{\circ}(001)$ and $\left.2 \theta=42.57^{\circ}(100)\right)$ correspond to the enlarged interlayer distance of $0.816 \mathrm{~nm}$ (the above distances were calculated using Bragg's law). The diffraction peaks in the XRD patterns of the pristine and modified TRGO are significantly widened because of the decrease in the crystallite sizes. To analyze these diffractograms, Gaussian fitting of the XRD peaks was performed. The main fitting parameters are presented in Table 3.

The fitting curves highlight some similarities and differences between the TRGO and modified samples. As can be seen from Fig. 3 and Table 3, the XRD pattern of TRGO-BDS most closely resembles that of TRGO. The same concerns the sample modified with $\mathrm{H}_{3} \mathrm{PO}_{4}$, although to a smaller extent. It means that during the modification, only small changes occur for the crystalline structure (probably because of the mild treatment conditions). For both samples treated with $\mathrm{H}_{2} \mathrm{SO}_{4}$, the shapes of their XRD patterns are similar, but evidently different from that of TRGO, which is a consequence of the aggressive character of this modifying agent. Similar observations were made after analyzing the SEM micrographs.

\subsubsection{TG analysis}

The thermal stability of the samples was evaluated by TG analysis. The results are depicted in Fig. 4.

As shown, the graphite powder is thermally stable over the entire temperature range (from room temperature to $800{ }^{\circ} \mathrm{C}$ ) as a very low weight loss of $1 \%$ takes place. The thermal stability of GO is significantly lower because of the presence of oxy-

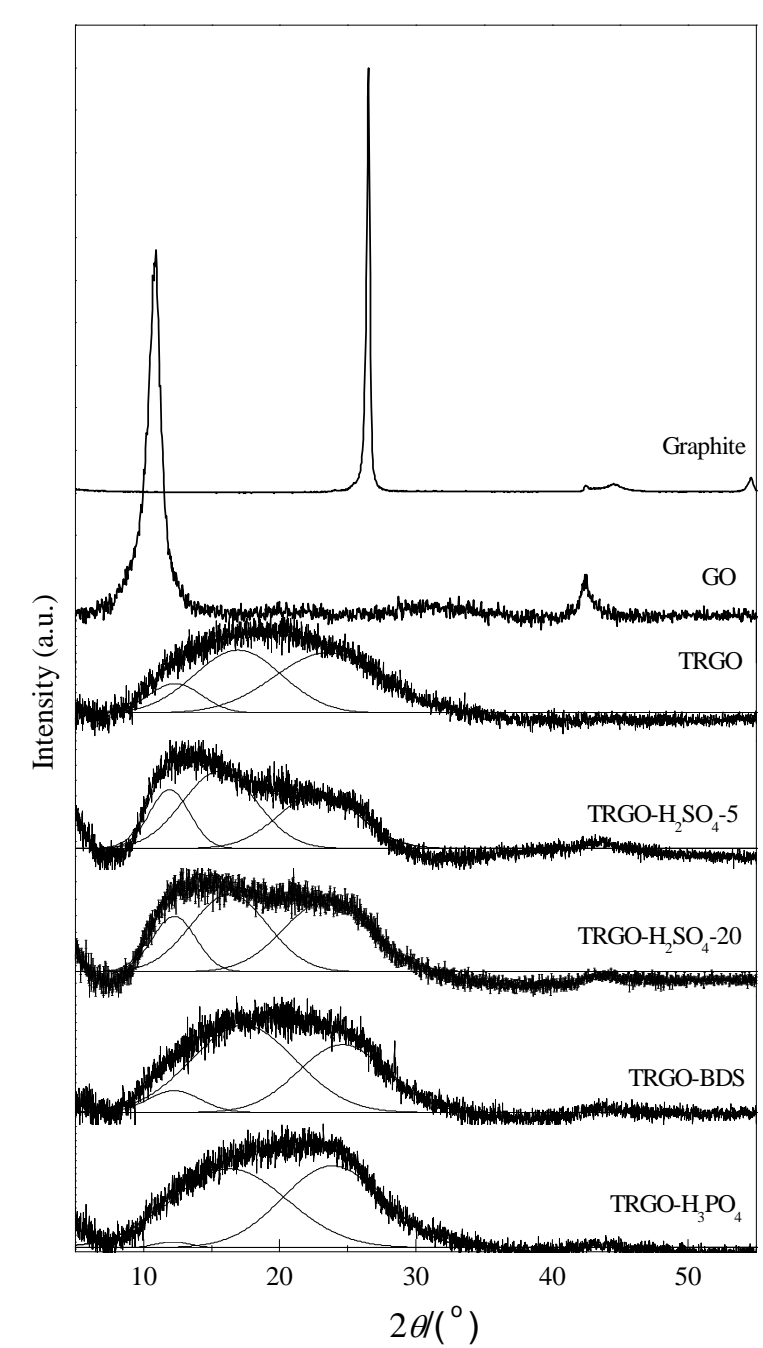

Fig. 3. XRD patterns of the precursor, intermediate products, and catalysts used in the transesterification reaction.

gen functional groups in its structure. The TG curve of GO shows three weight losses: at temperatures up to $150{ }^{\circ} \mathrm{C}$, in the range of $150-300{ }^{\circ} \mathrm{C}$, and above $300{ }^{\circ} \mathrm{C}$. The first one is attributed to evaporation of adsorbed water (GO is hydrophilic in nature [32]). The second one (the highest) corresponds to decomposition of surface labile oxygen functionalities (carboxyl, anhydride, or lactone groups). A slight weight loss observed > $300{ }^{\circ} \mathrm{C}$ can be ascribed to the decomposition of more stable oxygen groups (phenol, carbonyl, and quinone) that usually decompose at higher temperatures [33]. After the reduction, most of the oxygen-containing groups were removed from the

Table 3

Fitting results of the XRD patterns for TRGO and the modified samples.

\begin{tabular}{|c|c|c|c|c|c|c|c|c|c|}
\hline \multirow{2}{*}{ Sample } & \multicolumn{3}{|c|}{ Peak 1} & \multicolumn{3}{|c|}{ Peak 2} & \multicolumn{3}{|c|}{ Peak 3} \\
\hline & $2 \theta /\left(^{\circ}\right)$ & FWHM (a.u.) & Intensity (a.u.) & $2 \theta /\left(^{\circ}\right)$ & FWHM (a.u.) & Intensity (a.u.) & $2 \theta /\left({ }^{\circ}\right)$ & FWHM (a.u.) & Intensity (a.u.) \\
\hline TRGO & 12.32 & 4.60 & 0.037 & 16.95 & 7.60 & 0.079 & 23.55 & 9.25 & 0.076 \\
\hline TRGO- $\mathrm{H}_{2} \mathrm{SO}_{4}-5$ & 11.92 & 6.87 & 0.091 & 15.59 & 6.40 & 0.127 & 22.87 & 3.47 & 0.097 \\
\hline TRGO- $\mathrm{H}_{2} \mathrm{SO}_{4}-20$ & 12.25 & 3.75 & 0.083 & 16.31 & 6.62 & 0.116 & 23.44 & 7.32 & 0.107 \\
\hline TRGO-BDS & 12.25 & 4.53 & 0.063 & 17.34 & 9.00 & 0.253 & 24.62 & 7.66 & 0.197 \\
\hline TRGO- $\mathrm{H}_{3} \mathrm{PO}_{4}$ & 12.16 & 2.87 & 0.022 & 16.31 & 10.00 & 0.290 & 23.87 & 8.65 & 0.301 \\
\hline
\end{tabular}




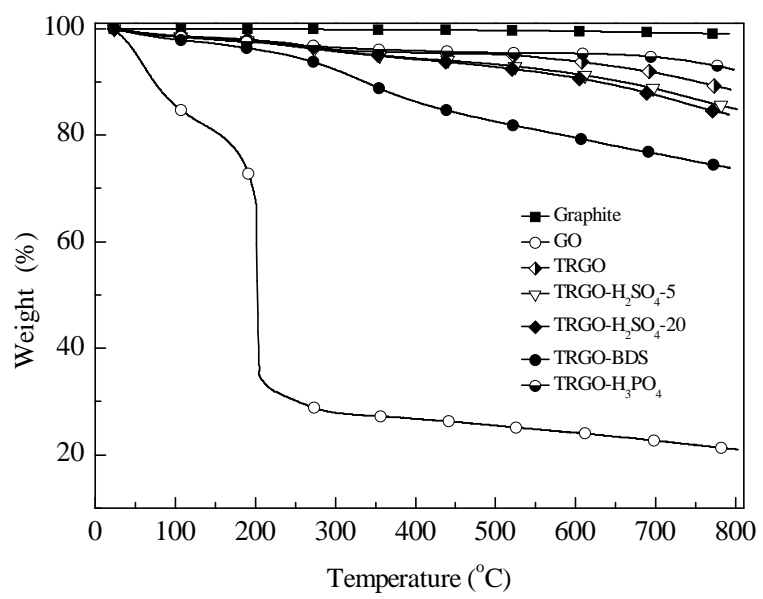

Fig. 4. TG analysis of graphite, intermediate products, and catalyst samples.

GO surface, so the derived TRGO exhibited less weight loss. The thermal decomposition of modified TRGO samples occurred mainly in the temperature range of $100-800{ }^{\circ} \mathrm{C}$ and may be ascribed to the pyrolysis of covalently bonded functional groups present on the TRGO surface. Among these materials, TRGO-BDS is the least thermally stable, which could be related to the higher content of surface functionalities than in the other cases, especially S-containing ones (Table 1). On the other hand, the TRGO- $\mathrm{H}_{3} \mathrm{PO}_{4}$ sample exhibited the greatest thermal stability up to $800{ }^{\circ} \mathrm{C}(\sim 8 \mathrm{wt} \%)$, and that was expected because this material was obtained at a very high temperature (see Section 2.2.4). A consequence of this treatment is the presence of only extremely thermally stable surface functionalities in the sample structure.

\subsubsection{FTIR analysis}

Fig. 5 shows FTIR spectra of the samples-GO, TRGO, and modified TRGO materials. For comparison, a spectrum of Amberlyst-15 is also presented.

The FTIR spectrum of the GO sample is consistent with the spectra reported elsewhere $[34,35]$. The most characteristic features of the spectrum are: a broad intense band at 3400 $\mathrm{cm}^{-1}$ (O-H stretching vibrations) and the bands at $1730 \mathrm{~cm}^{-1}$ ( $\mathrm{C}=0$ stretching vibrations from carbonyl and carboxyl groups), $1560 \mathrm{~cm}^{-1}$ (skeletal vibrations from unoxidized graphitic domains), $1226 \mathrm{~cm}^{-1}$ (C-OH stretching vibrations), and $1055 \mathrm{~cm}^{-1}$ (C-O-C stretching vibrations). Most of these peaks are also present in the TRGO, TRGO- $\mathrm{H}_{2} \mathrm{SO}_{4}-5$, TRGO- $\mathrm{H}_{2} \mathrm{SO}_{4}-20$, TRGO- $\mathrm{H}_{3} \mathrm{PO}_{4}$, and TRGO-BDS samples. The FTIR spectrum recorded for Amberlyst-15 shows characteristic vibrations corresponding to the presence of various structures. The peaks corresponding to uncoordinated water were found at $3433 \mathrm{~cm}^{-1}$ (symmetric and asymmetric $\mathrm{O}-\mathrm{H}$ stretching modes) and at $1646 \mathrm{~cm}^{-1}$ ( $\mathrm{H}-\mathrm{O}-\mathrm{H}$ bending modes). The presence of $-\mathrm{SO}_{3}-$ moieties is confirmed by the peaks at $1128,1008,834$, and 677 $\mathrm{cm}^{-1}$ [36]. The same group may be assigned to the peaks in the TRGO-BDS FTIR spectrum at 1120, 1043, 804, and $612 \mathrm{~cm}^{-1}$; meanwhile, these peaks are not visible in the spectra of TRGO- $\mathrm{H}_{2} \mathrm{SO}_{4}-5$ and TRGO- $\mathrm{H}_{2} \mathrm{SO}_{4}-20$ because they are most

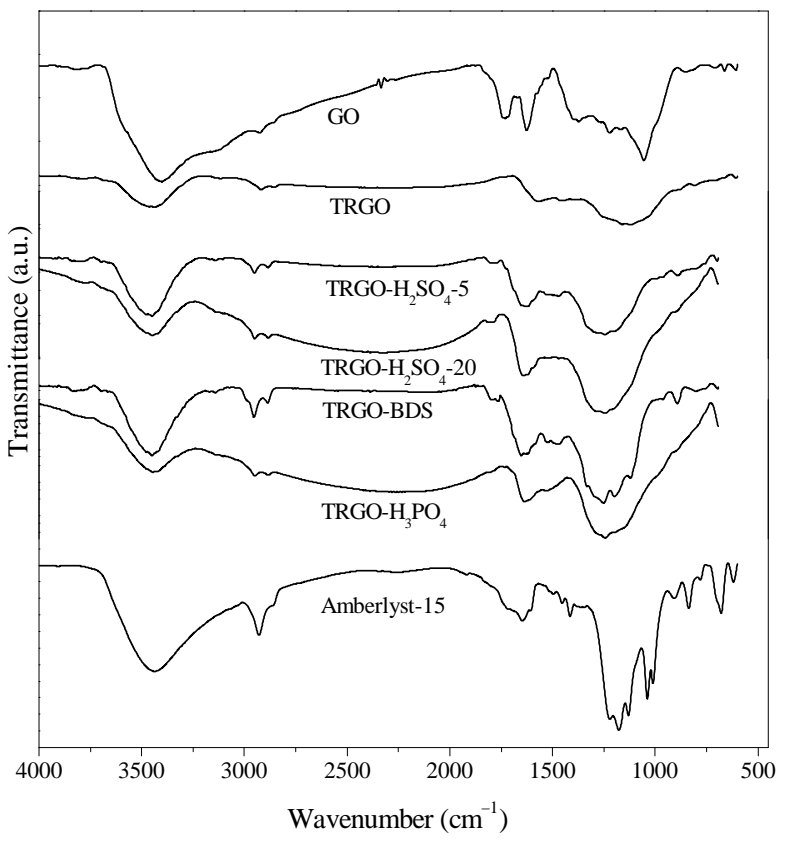

Fig. 5. FTIR spectra of the samples and a commercial catalyst (Amberlyst-15).

likely overlapped by the broad bands corresponding to oxygen linkages. The peak at $1175 \mathrm{~cm}^{-1}$, which is visible in the spectra of Amberlyst-15 and TRGO-BDS, reflects in-plane bending vibrations in 1,4-substituted aromatic rings, and thus confirms the presence of 4-benzenesulfonic acid moieties in these materials. The spectrum of TRGO- $\mathrm{H}_{3} \mathrm{PO}_{4}$ also contains broad bands, which make peak assignments more difficult.

\subsubsection{XPS investigations}

More detailed information on the type of oxygen, sulfur, and phosphorus functionalities present in the samples was provided by XPS analysis (Fig. 6, 7, and Table 4). According to the literature, XPS can be used to easily identify oxygen-containing functional groups in GO, TRGO, and their functionalized forms from spectral deconvolution of the $01 s$ or C $1 s$ XPS lines $[37,38]$. In this work, the $\mathrm{C} 1 \mathrm{~s}$ signal was used because it is difficult to unequivocally assign each of the deconvoluted $01 \mathrm{~s}$ peaks to a specific type of surface oxygen-containing group (probably because of the disturbing effect of the signals from the sorbed oxygen and water, and to a lesser degree from mineral substances [39]).

The $\mathrm{C} 1 s$ spectrum of the TRGO material (Fig. 6(a)) shows a main peak at a binding energy (BE) of $284.6 \mathrm{eV}$, which can be ascribed to carbon in the graphitic structure and aromatic rings ( $s p^{2}$ hybridization). This signal is also the most intense in the $\mathrm{C}$ $1 s$ spectra of the other samples (Fig. 6(b)-(d)), which means that in all cases, $s p^{2}$ is the main $\mathrm{C}$ bonding configuration that creates the graphitic structure. The peak at $285.9 \mathrm{eV}$ in the $\mathrm{C} 1 \mathrm{~s}$ spectrum of TRGO can be assigned to $\mathrm{C}-\mathrm{C}$ bonds of defects on the carbon structure $\left(s p^{3}\right)$. Two other small signals are associated with the presence of carbon atoms bonded to oxygen: the peak at $287.4 \mathrm{eV}$ is assigned to the $\mathrm{C}-\mathrm{O}$ groups in alcohols and phenol functionalities, and the signal at $288.7 \mathrm{eV}$ is attributed 

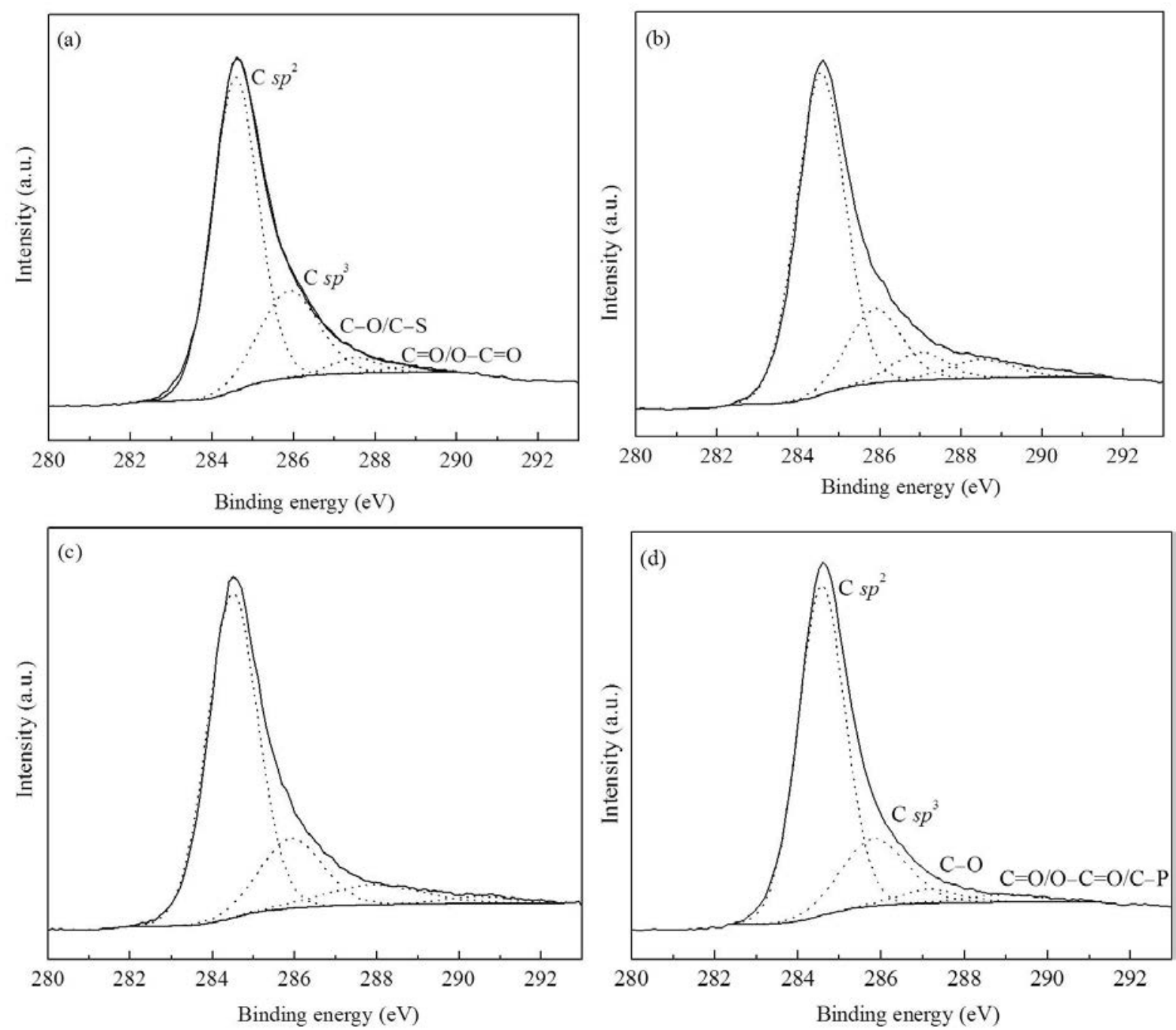

Fig. 6. $\mathrm{C} 1 s$ XPS spectra of TRGO (a), TRGO-H $2 \mathrm{SO}_{4}-20$ (b), TRGO-BDS (c), and $\mathrm{TRGO}^{-} \mathrm{H}_{3} \mathrm{PO}_{4}(\mathrm{~d})$.

to the $\mathrm{C}=0$ moieties in carbonyl or carboxylic groups [40]. It should also be noted that the $\mathrm{C} 1 \mathrm{~s}$ profiles do not show a broad weak component at around $292.0 \mathrm{eV}$, which comes from the $\pi$ $\rightarrow \pi *$ transition of carbon atoms in the graphene structure [40]. The same signals are present in the $\mathrm{C} 1 \mathrm{~s}$ spectra of the other samples (Fig. 6(b)-(d)). However, after the TRGO modifications, the peaks at 287.4 and $288.7 \mathrm{eV}$ are slightly shifted. Moreover, the concentration of these bands slightly increased (Table 4). Both these phenomena can be associated with the presence of S-containing functionalities (in the case of TRGO- $\mathrm{H}_{2} \mathrm{SO}_{4}-20$ and TRGO-BDS) or P-containing groups (in the case of TRGO- $\mathrm{H}_{3} \mathrm{PO}_{4}$ ) in the structure of the samples [41-44].

The $\mathrm{S}$ bands in the $\mathrm{S} 2 p$ region appear in the form of doublets because of the degeneration in the BE of the $2 p_{3 / 2}$ and $2 p_{1 / 2}$ orbitals. The $\mathrm{S} 2 p$ spectrum of TRGO is shown in Fig. 7(a). The high-resolution S $2 p$ XPS spectrum of TRGO is composed of two peaks: a lower energy doublet found at $164.6 \mathrm{eV}$ (S 2 $p_{1 / 2}$ ) and $163.7 \mathrm{eV}$ (S $2 p_{3 / 2}$ ), which is typical of sulfur in $\mathrm{C}-\mathrm{S}_{\mathrm{n}}-$ systems, and a higher energy doublet at 167.8 and $169.1 \mathrm{eV}$, which can be assigned to sulfonic acid/sulfate groups $\left(-\mathrm{SO}_{n}\right)$ [45]. The peak intensity of $\mathrm{C}-\mathrm{S}_{n}$ - is higher than that of $-\mathrm{SO}_{n}$, indicating that $\mathrm{C}-\mathrm{S}_{n}$ - is the dominant state of sulfur in TRGO. The observation of $-\mathrm{SO}_{n} / \mathrm{C}-\mathrm{S}_{n}$ - species at the surface of TRGO can be explained by the fact that the GO employed to prepare TRGO could contain residual intercalated $\mathrm{H}_{2} \mathrm{SO}_{4}$ and/or sulfates, which were not completely washed out after the oxidation step (Table 1). According to literature data, the products of $\mathrm{H}_{2} \mathrm{SO}_{4}$ thermal decomposition could recombine with oxygen groups on the carbon surface to form the species mentioned above $[46,47]$.

The modification of TRGO with $\mathrm{H}_{2} \mathrm{SO}_{4}$ does not significantly change the amounts of $\mathrm{C}_{-} \mathrm{S}_{n-}$ and $-\mathrm{SO}_{n}$ functionalities. These results may suggest that the sulfonation of graphene-like materials with this modifying agent is ineffective. However, the $-\mathrm{SO}_{n}$ peak corresponds to the presence of sulfonic and sulfate functionalities. As already discussed, residual sulfates could be present in TRGO, and the reaction of this sample with a strong acid could lead to sulfate removal. Thus, the almost constant content of sulfonic and sulfate groups in connection with the decrease in the content of sulfates may imply that some new sulfonic moieties are still formed. On the other hand, the TRGO modification with $\mathrm{BDS}$ drastically increased the amount of $-\mathrm{SO}_{n}$ 

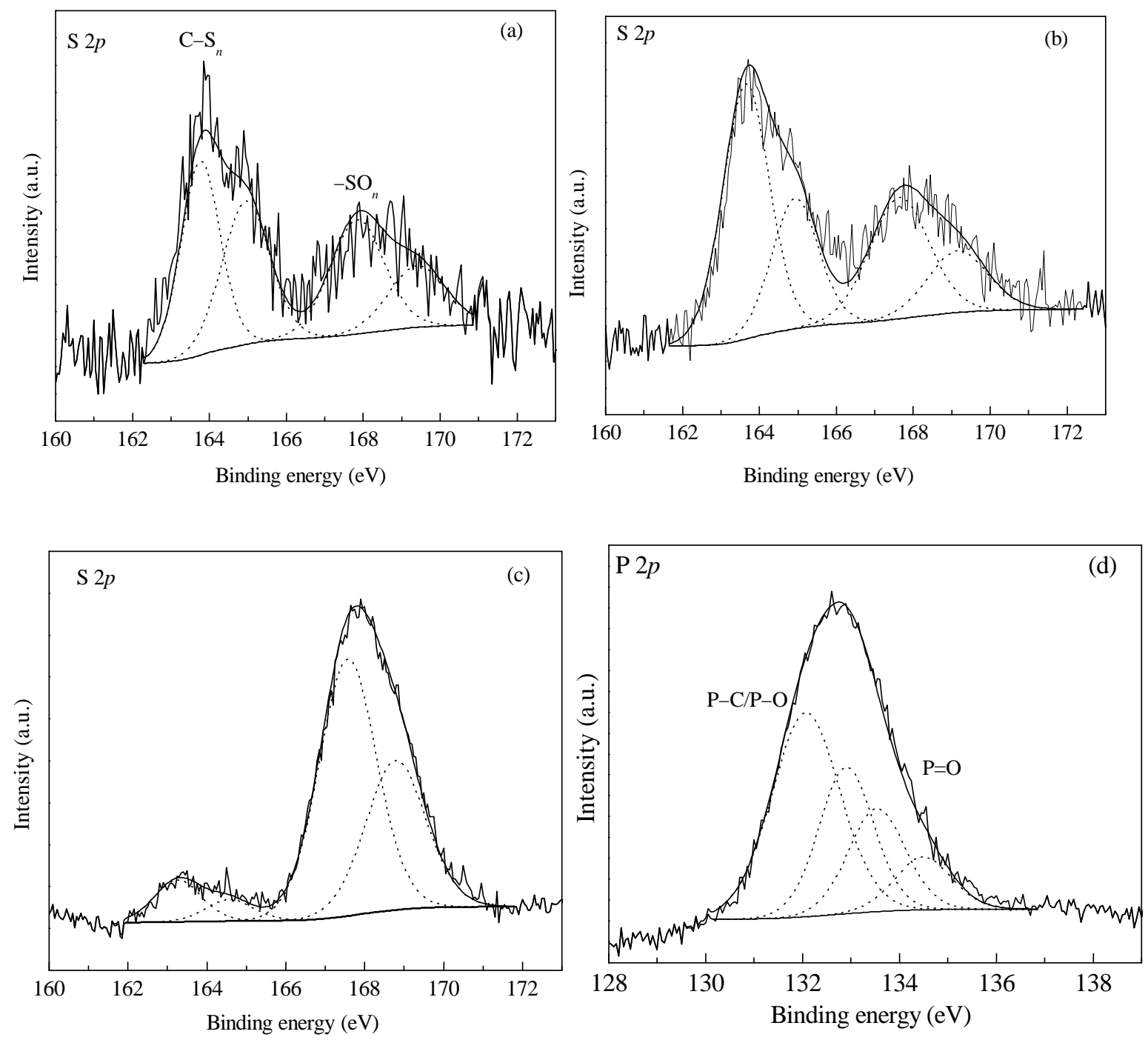

Fig. 7. S $2 p$ and P $2 p$ XPS spectra of TRGO (a), TRGO- $\mathrm{H}_{2} \mathrm{SO}_{4}-20$ (b), TRGO-BDS (c), and TRGO- $\mathrm{H}_{3} \mathrm{PO}_{4}$ (d).

groups from $0.4 \%$ to $3.0 \%$. The data presented above indicate that the surface density of the $-\mathrm{SO}_{n}$ species strongly depends on the functionalization methodology applied, and the TRGO modification with BDS seems to be a much more effective method of functionalization than the TRGO treatment with $\mathrm{H}_{2} \mathrm{SO}_{4}$. The results obtained are in full accordance with the analytical data presented in Table 1.

The high-resolution P $2 p$ XPS spectrum of the TRGO- $\mathrm{H}_{3} \mathrm{PO}_{4}$ sample is shown in Fig. 7(d). Deconvolution of the $\mathrm{P} 2 p$ region shows four peaks at 132.9 and $132.1 \mathrm{eV}$, and at 134.5 and 133.5 $\mathrm{eV}$, which correspond to the BEs of $\mathrm{P} 2 p_{1 / 2}$ and $\mathrm{P} 2 p_{3 / 2}$, respectively. All the phosphorus signals can be assigned to the presence of phosphate groups $(\mathrm{P}-\mathrm{C}, \mathrm{P}-\mathrm{O}-\mathrm{C}$, and $\mathrm{P}=0$ ) $[41,48]$, and thus confirm the effectiveness of TRGO modification with $\mathrm{H}_{3} \mathrm{PO}_{4}$.

The $\mathrm{N} 1 s$ region of the TRGO-BDS sample (spectrum not presented) shows only one peak at $400.5 \mathrm{eV}$, which can be assigned to $-\mathrm{N}=\mathrm{N}-$ species [49]. The presence of the $\mathrm{N} 1 \mathrm{~s}$ signal for carbon modified with BDS indicates that the decomposition of the diazonium salt during the grafting process was incomplete. Therefore, we conclude that the aryl groups are bonded to the carbon structure not only by $\mathrm{C}-\mathrm{C}$ but also via $-\mathrm{N}=\mathrm{N}-$ bonds, which was also confirmed by the EA results presented earlier.

\subsection{Catalytic tests}

The modified graphene-based catalysts were tested in the transesterification reaction of rapeseed oil with methanol. The yields of FAMEs obtained in the process versus reaction time are given in Fig. 8. For sake of comparison, the results obtained with the use of the commercial catalyst, Amberlyst-15, are also presented in the graph.

As depicted, for most of the samples, the yield of FAME increases significantly with the reaction time and reaches a plateau after several hours of the process. The only exception is for TRGO, whose activity is very low during the entire reaction and increases only slightly with time. The catalytic activities of the 
Table 4

Analysis of the high-resolution XPS spectra of the obtained catalysts.

\begin{tabular}{|c|c|c|c|c|c|c|c|c|c|}
\hline \multirow{3}{*}{ Sample } & \multicolumn{9}{|c|}{$\mathrm{BE}, \mathrm{eV}$ (concentration of species, at $\%$ ) } \\
\hline & \multicolumn{4}{|c|}{$\mathrm{C} 1 \mathrm{~s}$} & \multirow{2}{*}{$\frac{\mathrm{S} 2 p^{\mathrm{a}}}{\mathrm{C}-\mathrm{S}_{n}{ }^{\mathrm{b}}}$} & \multicolumn{3}{|c|}{$\mathrm{P} 2 p^{\mathrm{a}}$} & \multirow{2}{*}{$\begin{array}{c}\mathrm{N} 1 s \\
-\mathrm{N}=\mathrm{N}-\end{array}$} \\
\hline & $\mathrm{C}=\mathrm{C}$ & $\mathrm{C}-\mathrm{C}$ & $\mathrm{C}-\mathrm{O} / \mathrm{C}-\mathrm{S}$ & $\mathrm{C}=0 / \mathrm{O}-\mathrm{C}=\mathrm{O} / \mathrm{C}-\mathrm{P}$ & & $-\mathrm{SO}_{n}$ & $\mathrm{P}-\mathrm{C} / \mathrm{P}-\mathrm{O}$ & $\mathrm{P}=0$ & \\
\hline TRGO & 284.6 & 285.9 & 287.4 & 288.7 & 163.7 & 167.8 & - & - & - \\
\hline TRGO- $\mathrm{H}_{2} \mathrm{SO}_{4}-20$ & $\begin{array}{l}284.6 \\
(61.4)\end{array}$ & $\begin{array}{l}285.9 \\
(15.6)\end{array}$ & $\begin{array}{c}287.0 \\
(5.9)\end{array}$ & $\begin{array}{c}288.5 \\
(4.8)\end{array}$ & $\begin{array}{c}163.7 \\
(0.8)\end{array}$ & $\begin{array}{c}167.8 \\
(0.3)\end{array}$ & - & - & - \\
\hline TRGO-BDS & $\begin{array}{l}284.6 \\
(57.3)\end{array}$ & $\begin{array}{l}285.9 \\
(15.3)\end{array}$ & $\begin{array}{c}287.9 \\
(6.9)\end{array}$ & $\begin{array}{c}290.2 \\
(1.7)\end{array}$ & $\begin{array}{c}163.7 \\
(0.3)\end{array}$ & $\begin{array}{c}167.8 \\
(3.0)\end{array}$ & - & - & $\begin{array}{c}400.5 \\
(0.6)\end{array}$ \\
\hline TRGO- $\mathrm{H}_{3} \mathrm{PO}_{4}$ & 284.6 & 285.9 & 287.1 & 289.0 & - & - & 132.1 & 133.5 & - \\
\hline
\end{tabular}

a For the $\mathrm{S} 2 p$ and $\mathrm{P} 2 p$ orbitals, the $\mathrm{BE}$ of the $2 p_{3 / 2}$ orbital is presented;

${ }^{\mathrm{b}} n=1$ or 2 .

prepared samples vary considerably, and the FAME yields obtained after $24 \mathrm{~h}$ with the produced materials are in the range of $2 \%-80 \%$. GO synthesized from graphite through its oxidation with different reagents (see Section 2.2.1) shows a high catalytic performance. This can be a consequence of the presence of S-containing moieties in the structure of GO (Table 1). As suggested earlier, GO may contain residual intercalated $\mathrm{H}_{2} \mathrm{SO}_{4}$ that was not completely washed out after the oxidation step apparently; its presence is responsible for the relatively high FAME yield. The thermal reduction of GO must result in a significant removal of $\mathrm{H}_{2} \mathrm{SO}_{4}$ from the sample structure, which is manifested by a drop in the total acidity. As a consequence, TRGO shows only a negligible catalytic activity (about 3\% after $24 \mathrm{~h}$ of reaction).

As depicted in Fig. 8, modifications of TRGO to endow the surface with acidic properties result in significant improvements in the catalytic activity of the obtained samples. Furthermore, the type of applied modification strongly influences the catalytic performance of the produced materials. In the case of samples modified with concentrated $\mathrm{H}_{2} \mathrm{SO}_{4}$, higher yields of FAME were obtained after longer treatment times; for TRGO- $\mathrm{H}_{2} \mathrm{SO}_{4}-5$, the FAME yield was about $31 \%$, and for TRGO- $\mathrm{H}_{2} \mathrm{SO}_{4}-20$, this parameter was about $46 \%$. However, it should be stressed that these catalysts differ only slightly considering the content of elements and total acidity. Apparently,

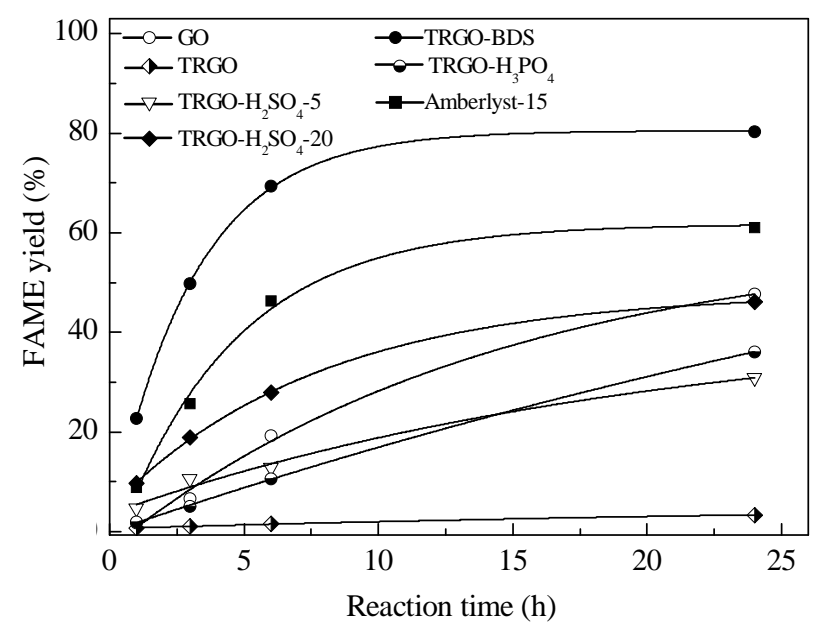

Fig. 8. Comparison of the FAME yields obtained for the graphene-based catalysts and a commercial catalyst Amberlyst-15. even such small differences in the acidic properties of the samples can result in significant changes in their catalytic activities.

It is clearly visible from Fig. 8 that the sample functionalized with BDS shows the best catalytic activity in the process of rapeseed oil transesterification. After $24 \mathrm{~h}$ of reaction, the yield of FAME is about $80 \%$. This result is even better than that attained using a commercial catalyst, Amberlyst-15 (60\% after $24 \mathrm{~h}$ ), despite a much higher content of acidic groups on the surface of Amberlyst-15 (4.70 mmol/g) than on the surface of TRGO-BDS (1.46 mmol/g). The higher catalytic activity of TRGO-BDS may be associated with its unique two-dimensional sheet structure where most of the $-\mathrm{SO}_{3} \mathrm{H}$ groups are well dispersed and exposed to reactants during the process. On the other hand, Amberlyst-15 has a porous structure with a much lower $S_{\mathrm{BET}}$ than TRGO-BDS (Table 2). As a consequence, some of the $-\mathrm{SO}_{3} \mathrm{H}$ groups on this catalyst might not be accessible to reactants, which must lead to a lower product yield.

The sample modified with $\mathrm{H}_{3} \mathrm{PO}_{4}$ shows a relatively low catalytic activity (FAME yield after $24 \mathrm{~h}$ of about $36 \%$ ), although the total acidity of TRGO- $\mathrm{H}_{3} \mathrm{PO}_{4}$ was rather high $(1.38 \mathrm{mmol} / \mathrm{g}$; Table 1). The moderate catalytic performance of TRGO- $\mathrm{H}_{3} \mathrm{PO}_{4}$ must be a consequence of the lower acid strength of the phosphate groups in comparison with that of the sulfonic groups. Thus, the results clearly indicate that the concentration of acid sites and their strength is essential in biodiesel synthesis using the transesterification reaction.

When analyzing the efficiency of the transesterification reaction, another important thing should be considered-the time after which the reaction reaches a satisfactory yield. On the basis of the results depicted in Fig. 8, the best catalyst among the materials tested is TRGO-BDS. In this case, a very high FAME yield is obtained after a relatively short period of time, e.g., about $70 \%$ after $6 \mathrm{~h}$, whereas a FAME yield achieved for the commercial catalyst, Amberlyst-15, after the same time is only about $46 \%$. Thus, from an economic point of view, the use of TRGO-BDS in the biodiesel synthesis may be viable. It can also be supposed that this catalyst will show a great catalytic potential in other reactions that require the presence of strong acidic sites.

Apart from the catalytic activity, the reusability of a catalyst is of great importance because it has a huge impact on the general costs of biodiesel production. The stability of the TRGO-BDS catalyst in the transesterification reaction was as- 


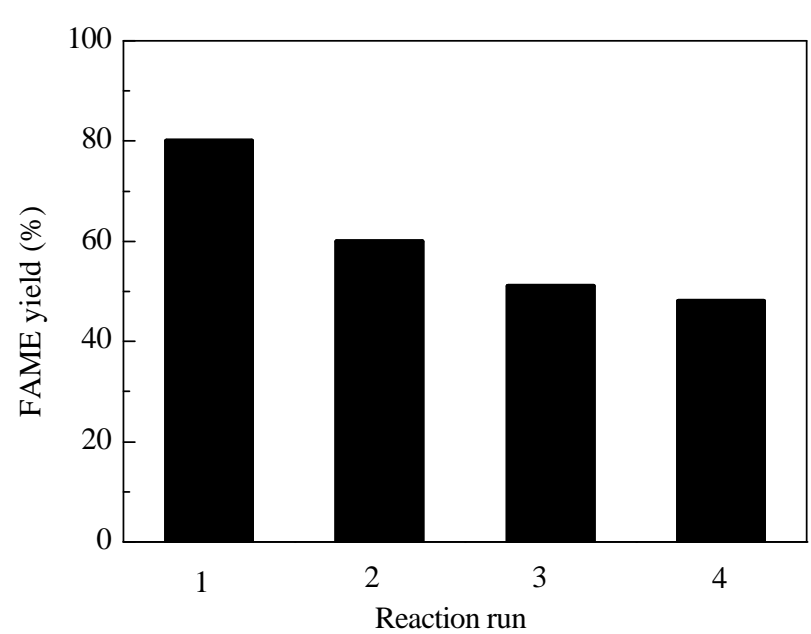

Fig. 9. FAME yields obtained after $24 \mathrm{~h}$ of transesterification of rapeseed oil with methanol in the presence of TRGO-BDS in four recycling runs.

sessed in four sequential reuse tests. The results are displayed in Fig. 9. As can be seen, the activity of TRGO-BDS diminished significantly after the first reaction cycle; however, the material still showed good catalytic properties (the FAME yield was reduced from $80 \%$ to $60 \%$ ). The catalyst deactivation also occurred in subsequent recycling runs, but it was not significant (the yields of FAME from the 3rd and 4th runs are similar and relatively high).

To find out the reason for catalyst deactivation, TRGO-BDS was subjected to EA and potentiometric titration after four recycling runs. On the basis of these results, it can be concluded that the deactivation was mainly caused by the partial removal of sulfonic groups from the catalyst structure. This was indicated by the drop in sulfur content (from 4.7 to $2.7 \mathrm{wt} \%$ ) and decrease in the total acidity (from 1.46 to $0.97 \mathrm{mmol} / \mathrm{g}$ ). However, it should be stressed that the total acidity of the TRGO-BDS sample after four recycling runs was still quite high and is the reason for the considerable FAME yield obtained from the 4th experiment. As suggested in the literature, the other cause of catalyst deactivation may be the accumulation of impurities or by-products, such as oil, FAME, glycerol, and FFAs, on the catalyst surface [50]. Confirmation of this hypothesis can be found from the decrease in $S_{\mathrm{BET}}$ and $V_{\text {tot }}$ for TRGO-BDS after four recycling runs (Table 2). On the other hand, some authors suggest that neutralization of acidic functional groups on the catalyst surface can also occur during the transesterification reaction, e.g., by the formation of methyl esters of sulfonic acid [51]. This phenomenon could be also confirmed by the aforementioned drop in the total acidity of the catalyst.

\section{Conclusions}

Acidic graphene-based catalysts were prepared by functionalization of TRGO with concentrated $\mathrm{H}_{2} \mathrm{SO}_{4}$, BDS, or $\mathrm{H}_{3} \mathrm{PO}_{4}$. It was found that the type of groups introduced to the graphene structure as well as their amount significantly depended on the modification method and the treatment conditions. It was demonstrated that concentrated $\mathrm{H}_{2} \mathrm{SO}_{4}$ was a weak sulfonating agent for typical graphene materials. A more promising procedure was TRGO modification via diazonium salt generated in situ. The sample prepared by this method showed a good catalytic activity in the transesterification of rapeseed oil with methanol towards biodiesel formation (the yield of FAME after $24 \mathrm{~h}$ was up to $80 \%$ ). Comparing to other catalysis, in this case, the reaction rate was quite high and after only $6 \mathrm{~h}$ of the process, the FAME yield was about 70\%. It is worth noting that the results obtained for the best sample were significantly higher than those achieved with the commercial catalyst, Amberlyst-15. The materials modified with concentrated $\mathrm{H}_{2} \mathrm{SO}_{4}$ or $\mathrm{H}_{3} \mathrm{PO}_{4}$ showed a considerably lower activity during the process. It can be concluded that the concentration of acidic sites and their strengths are essential for FAME synthesis. The reusability studies showed that TRGO-BDS was stable in the subsequent reaction cycles. Both leaching and neutralization of active sites, and the adsorption of impurities or by-products on the catalyst surface were suggested to be responsible for the observed deactivation of the graphene-based materials.

\section{Acknowledgments}

The authors thank The Education Exchanges Support Foundation for the national scholarship $f$ the LR Ministry of Education and Science. Agrement No. AM-PL-2014-LT-1225.

\section{References}

[1] L. Lin, C. S. Zhou, S. Vittayapadung, X. Q. Shen, M. d. Dong, Appl. Energy, 2011, 88, 1020-1031.

[2] A. Demirbas, Energy Convers. Manag., 2009, 50, 14-34.

[3] S. N. Gebremariam, J. M. Marchetti, AIMS Energy, 2017, 5, 425-457.

[4] Y. M. Sani, W. M. A. W. Daud, A. R. Abdul Aziz, Appl. Catal., 2014, $470,140-161$.

[5] A. M. Ruhul, M. A. Kalam, H. H. Masjuki, I. M. R. Fattah, S. S. Reham, M. M. Rashed, RSC Adv., 2015, 5, 101023-101044.

[6] L. Liu, Y. P. Zhu, M. Su, Z. Y. Yuan, ChemCatChem, 2015, 7, 2765-2787.

[7] X. Y. Sun, R. Wang, D. S. Su, Chin. J. Catal., 2013, 34, 508-523.

[8] B. Garg, Y. C. Ling, Green Mater., 2013, 1, 47-61.

[9] P. Serp, J. L. Figueiredo, Carbon Materials for Catalysis, John Wiley \& Sons, Hoboken, N. J., 2009.

[10] L. J. Konwar, J. Boro, D. Deka, Renew. Sust. Energy Rev., 2014, 29, 546-564.

[11] N. F. Goldshleger, Fullerene Sci. Technol., 2001, 9, 255-280.

[12] Y. B. Yan, J. W. Miao, Z. H. Yang, F. X. Xiao, H. B. Yang, B. Liu, Y. H. Yang, Chem. Soc. Rev., 2015, 44, 3295-3346.

[13] J. Y. Ji, G. H. Zhang, H. Y. Chen, S. L. Wang, G. L. Zhang, F. B. Zhang, X. B. Fan, Chem. Sci., 2011, 2, 484-487.

[14] H. Liu, J. Z. Chen, L. M. Chen, Y. S. Xu, X. H. Guo, D. Y. Fang, ACS Sustainable Chem. Eng., 2016, 4, 3140-3150.

[15] M. J. Allen, V. C. Tung, R. B. Kaner, Chem. Rev., 2010,110, 132-145.

[16] B. F. Machado, P. Serp, Catal. Sci. Technol., 2012, 2, 54-75.

[17] M. Z. Cai, D. Thorpe, D. H. Adamson, H. C. Schniepp, J. Mater. Chem., 2012, 22, 24992-25002.

[18] D. R. Dreyer, S. Park, C. W. Bielawski, R. S. Ruoff, Chem. Soc. Rev., 


\section{Graphical Abstract}

Chin. J. Catal., 2018, 39: 1633-1645 doi: 10.1016/S1872-2067(18)63087-6

\section{Modified graphene-based materials as effective catalysts for transesterification of rapeseed oil to biodiesel fuel}

Justina Gaidukevič *, Jurgis Barkauskas, Anna Malaika *, Paulina Rechnia-Gorący, Aleksandra Możdżyńska, Vitalija Jasulaitienė, Mieczysław Kozłowski

Vilnius University, Lithuania; Adam Mickiewicz University in Poznań, Poland;

State Research Institute Centre for Physical Sciences and Technology, Lithuania

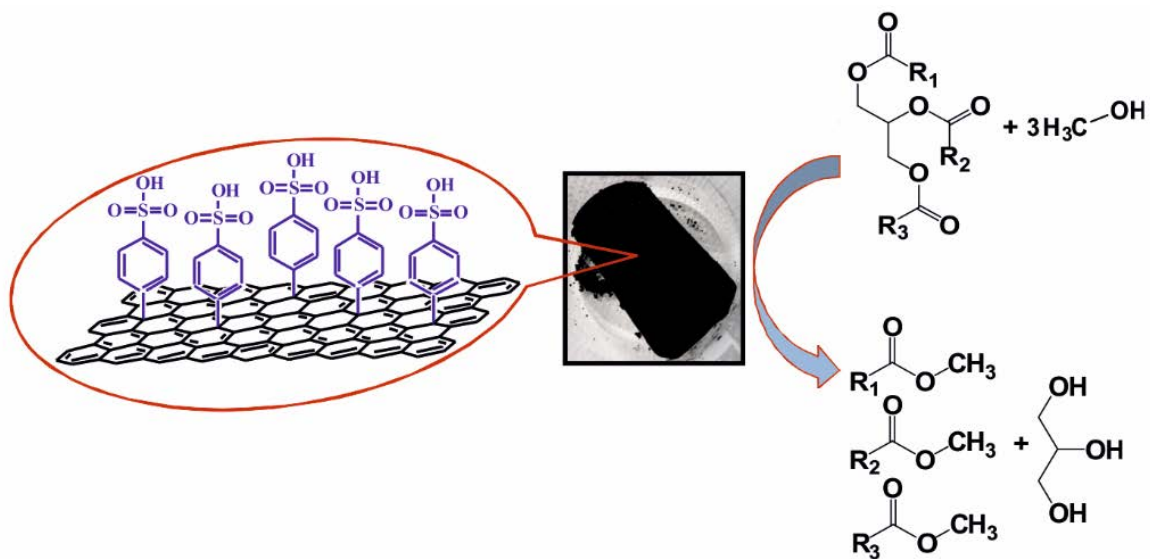

Graphene-based acidic catalysts exhibit a high performance and good stability in the transesterification reaction, which make them promising catalysts for biodiesel fuel production.

2010, 39, 228-240.

[19] M. C. Nongbe, T. Ekou, L. Ekou, K. B. Yao, E. Le Grognec, F. X. Felpin, Renew. Energy, 2017, 106, 135-141.

[20] X. B. Yan, J. T. Chen, J. Yang, Q. J. Xue, P. Miele, ACS Appl. Mater. Interfaces., 2010, 2, 2521-2529.

[21] W. S. Hummers, R. E. Offeman, J. Am. Chem. Soc., 1958, 80, 1339-1339.

[22] I. Sakinyte, J. Barkauskas, J. Gaidukevic, J. Razumiene, Talanta, 2015, 144, 1096-1103.

[23] M. Toupin, D. Belanger, Langmuir, 2008, 24, 1910-1917.

[24] A. M. Puziy, O. I. Poddubnaya, B. Gawdzik, M. Sobiesiak, M. M. Tsyba, Adsorpt. Sci. Technol., 2007, 25, 531-542.

[25] S. J. Gregg, K. S. W. Sing, H. W. Salzberg, J. Electrochem. Soc., 1967, 114, 279C.

[26] T. Furusawa, F. Kurayama, H. Handa, R. Kadota, M. Sato, N. Suzuki, Appl. Catal. A, 2014, 475, 69-75.

[27] J. L. Figueiredo, M. F. R. Pereira, M. M. A. Freitas, J. J. M. Órfão, Carbon, 1999, 37, 1379-1389.

[28] G. S. Szymański, Z. Karpiński, S. Biniak, A. Świątkowski, Carbon, 2002, 40, 2627-2639.

[29] X. H. Mo, D. E. López, K. Suwannakarn, Y. J. Liu, E. Lotero, J. G. Goodwin Jr, C. Q. Lu, J. Catal., 2008, 254, 332-338.

[30] P. Rechnia, A. Malaika, M. Kozłowski, Fuel, 2015, 154, 338-345.

[31] M. Toupin, D. Bélanger, J. Phys. Chem. C, 2007, 111, 5394-5401.

[32] T. Soltani, B. K. Lee, J. Colloid Interface Sci., 2017, 486, 337-343.

[33] K. Haubner, J. Murawski, P. Olk, L. M. Eng, C. Ziegler, B. Adolphi, E. Jaehne, ChemPhysChem, 2010, 11, 2131-2139.

[34] P. G. Ren, D. X. Yan, X. Ji, T. Chen, Z. M. Li, Nanotechnology, 2011, 22, 055705.

[35] J. I. Paredes, S. Villar-Rodil, A. Martínez-Alonso, J. M. D. Tascón,
Langmuir ACS J. Surf. Colloids, 2008, 24, 10560-10564.

[36] I. A. Salem, Chemosphere, 2001, 44, 1109-1119.

[37] R. Trusovas, G. Račiukaitis, G. Niaura, J. Barkauskas, G. Valušis, R. Pauliukaite, Adv. Opt. Mater., 2016, 4, 37-65.

[38] H. P. Boehm, Carbon, 2002, 40, 145-149.

[39] M. Kozłowski, Fuel, 2004, 83, 259-265.

[40] H. Gaspar, C. Pereira, S. L. H. Rebelo, M. F. R. Pereira, J. L. Figueiredo, C. Freire, Carbon, 2011, 49, 3441-3453.

[41] J. Bassil, S. Roualdès, V. Flaud, J. Durand, J. Membr. Sci., 2014, 461, 1-9.

[42] Y. Chen, J. Li, T. Mei, X. G. Hu, D. W. Liu, J. C. Wang, M. Hao, J. H. Li, J. Y. Wang, X. B. Wang, J. Mater. Chem. A, 2014, 2, 20714-20722.

[43] J. N. Hart, P. W. May, N. L. Allan, K. R. Hallam, F. Claeyssens, G. M. Fuge, M. Ruda, P. J. Heard, J. Solid State Chem., 2013, 198, 466-474.

[44] X. M. Li, S. P. Lau, L. B. Tang, R. B. Ji, P. Z. Yang, Nanoscale, 2014, 6 , 5323-5328.

[45] W. F. Deng, Y. J. Zhang, L. Yang, Y. M. Tan, M. Ma, Q. J. Xie, RSC Adv., 2015, 5, 13046-13051.

[46] A. P. Terzyk, J. Colloid Interface Sci., 2003, 268, 301-329.

[47] F. Barroso-Bujans, J. L. G. Fierro, S. Rojas, S. Sánchez-Cortes, M. Arroyo, M. A. López-Manchado, Carbon, 2007, 45, 1669-1678.

[48] X. M. Fan, C. Yu, Z. Ling, J. Yang, J. S. Qiu, ACS Appl. Mater. Interfaces, 2013, 5, 2104-2110.

[49] S. Kesavan, S. Abraham John, J. Colloid Interface Sci., 2014, 428, 84-94.

[50] L. Peng, A. Philippaerts, X. X. Ke, J. Van Noyen, F. De Clippel, G. Van Tendeloo, P. A. Jacobs, B. F. Sels, Catal. Today, 2010, 150, 140-146.

[51] J. M. Fraile, E. García-Bordejé, L. Roldán, J. Catal., 2012, 289, 73-79. 


\title{
改进的石墨烯基材料用作菜䊏油转酯化反应制生物柴油的有效催化剂
}

\author{
Justina Gaidukevič a, ${ }^{\text {, }}$, Jurgis Barkauskas ${ }^{\text {a }}$, Anna Malaika b,\#, Paulina Rechnia-Gorący ${ }^{\text {b, }}$ \\ Aleksandra Możdżyńska ${ }^{\mathrm{b}}$, Vitalija Jasulaitiené ${ }^{\mathrm{c}}$, Mieczysław Kozłowski ${ }^{\mathrm{b}}$ \\ a维尔纽斯大学化学研究所化学与地学系, 瑙加杜科 24, 维尔纽斯LT-03225, 立陶宛 \\ b 波兹南密茨凯维奇大学化学系, 乌穆托斯卡89b, 波茨纳61-614, 波兰 \\ c 物理科学技术国家研究中心, 撒乌耳.特基奥3, 维尔纽斯LT-10257, 立陶宛
}

\begin{abstract}
摘要: 本文研究了不同石墨烯基材料用作转酯化反应制备生物柴油催化剂的性能. 将磺酸基或磷酸盐基嫁接到热还原的 氧化石墨烯表面, 制备了固体酸石墨烯基样品. 并采用扫描电镜、X射线衍射、热重分析、X射线光电子能谱、 $\mathrm{N}_{2}$ 吸附-脱 附法、电位滴定法、元素分析以及红外光谱法对所制样品进行了全面表征. 将所制样品用于 $130^{\circ} \mathrm{C}$ 带压力的条件下菜䊏油 与甲醇转酯化反应中, 并将其催化活性与商用的多相酸催化剂Amberlyst-15的进行了比较. 结果表明, 所有改进的样品在 转酯化反应中均表现出催化活性, 但各样品上生物柴油产率差别较大. 其中以苯二氮磺酸基功能化的热还原氧化石墨烯 样品上脂肪酸甲酯产率最高, 反应 $6 \mathrm{~h}$ 后达 $70 \%$, 也明显高于商用催化剂Amberlyst-15. 该样品也表现出良好的重复使用性 能.
\end{abstract}

关键词: 石墨烯; 表面官能团化; 酸催化剂; 磺酸基; 转酯化; 生物柴油

收稿日期: 2018-03-23. 接受日期: 2018-04-17. 出版日期: 2018-10-05.

*通讯联系人. 电话: +370-5-2234610; 电子信箱: justina.gaidukevic@chf.vu.lt

\#通讯联系人. 电子信箱: amalaika@amu.edu.pl

本文的电子版全文由Elsevier出版社在ScienceDirect上出版(http://www.sciencedirect.com/science/journal/18722067). 